\title{
Surgical anatomy of the recurrent laryngeal nerve; a cross-sectional descriptive study
}

\author{
Sunanda H, Tilakeratne S, De Silva KPVR \\ Teaching Hospital, Karapitiya, Galle. \\ Corresponding author; Dr.H.Sunanda (sunanda.hediwattege@gmail.com)
}

\begin{abstract}
Objective: To describe the relationship of the recurrent laryngeal nerve (RLN) to the inferior thyroid artery and the ligament of Berry and to study its trajectory

Method: Twenty patients who underwent total thyroidectomy and six who underwent thyroid lobectomy were included. 46 RLNs including 24 right and 22 left, were studied. The relationship of the nerve to the inferior thyroid artery, ligament of Berry and its course between these two structures were recorded after the surgery. Data were tabulated and analyzed using spread sheet application.

Results: In 28 instances ( $61 \% ; 80 \%$ of left and $50 \%$ of right), the nerve was posterior to the inferior thyroid artery while in 11 occasions $(24 \% ; 33 \%$ of right and $15 \%$ of left $)$ the nerve traveled through the branches of the inferior thyroid artery. In four instances, $(9 \%)$ the nerve was anterior to the inferior thyroid artery. In one instance, a single right non-recurrent laryngeal nerve $(2 \%)$ was detected. The left inferior thyroid artery was absent in two patients. In 25 instances (54\%), the nerve was in contact with the Berry's ligament while in 17 (37\%) occasions the nerve traveled in between the ligament and tracheo-oesophagial groove (TO groove) and in 3 instances (7\%), the nerve traveled through the ligament. The observed right non-recurrent nerve $(2 \%)$ was superior to the ligament. The trajectory of the RLN from the inferior thyroid artery level to the ligament of Berry fell into eight categories. In $70 \%$ instances, RLN (77\% of left and $63 \%$ of right) was in the tracheo-oesophageal groove at the inferior thyroid artery level.

Conclusions: RLN is usually posterior to the inferior thyroid artery. Relationship between right RLN and the inferior thyroid artery is more variable than that between the left RLN and inferior thyroid artery. RLN is commonly in contact with the ligament of Berry. Most of the time (79\%) the left RLN was found to be in the TO groove, deep to the inferior thyroid artery while the right RLN showed a more variable position. The trajectory of the nerve from the inferior thyroid artery level to the level of ligament of Berry was highly variable. Occasionally, the presence of the right non recurrent laryngeal nerve should be expected.
\end{abstract}

\section{Key words: Recurrent laryngeal nerve, inferior thyroid artery, ligament of Berry.}

\section{Introduction}

The recurrent laryngeal nerve (RLN) was first described by Galen. Iatrogenic injury to the RLN is one of the most dreaded complications of thyroidectomy. Knowledge of the anatomy of the RLN and its variations is of great important to prevent iatrogenic damage to the nerve. Careful exploration and exact identification of the RLN reduce the risk of accidental nerve damage by 3 to 4 times. Most of the studies done regarding the anatomy of the RLN are cadaveric studies. Surgical anatomy of the RLN is different from normal anatomy since it is explored after the thyroid lobe is delivered. In this study we describe the surgical anatomy of 46 recurrent laryngeal nerves.

\section{Objective}

The main objective of the study was to determine the relationship of the RLN to the inferior thyroid artery and the ligament of Berry. Also we wished to study the trajectory of the nerve between these two structures.

Galle Medical Journal, Vol 15: No. 1, September 2010 


\section{Methods}

Twenty patients who underwent total extra capsular thyroidectomy and six patients who underwent lobectomy plus isthmectomy were included in the study. 25 of them were females. 22 right and 24 left RLNs were studied. The RLN was closely observed during surgery and the relationship and the pathway was accurately drawn immediately after the surgery. The data were tabulated and analyzed by drawing pie charts.

All patients were operated by the same surgical team and same surgical approach was adopted in all. None of the subjects had undergone surgical procedures in the neck region previously. The first point of exploration of the nerve was at the inferior thyroid artery. The RLN was detected bilaterally in all the patients. After identification it was tunneled up. In our experience this approach leads to high identification rate and zero damage rate of the RLN.

\section{Results}

In $28(61 \%)$ instances, the nerve ( $80 \%$ of left and $50 \%$ of right) was posterior to the inferior thyroid artery while in $11(24 \%)$ instances (33\% of right and $15 \%$ of left) the nerve traveled through the branches of the inferior thyroid artery and 4 nerves $(9 \%)$ were anterior to the artery. In one occasion a right non recurrent laryngeal nerve was detected. The left inferior thyroid artery was absent in two patients $(3.8 \%)$.

In $25(54 \%)$ instances, the nerve was in contact with the Berry's ligament while in 17 (37\%) instances the nerve traveled in between the ligament and tracheooesophageal groove (TO groove) and three RLNs (7\%) traveled through the ligament. The observed right non-recurrent nerve was superior to the ligament. Most of the time (79\%), the left RLN was found to be in the TO groove, deep to the inferior thyroid artery while the right RLN showed a more variable position.

Table: Trajectory of the RLN between the inferior thyroid artery and the ligament of Berry

\begin{tabular}{|l|r|r|r|}
\hline \multicolumn{1}{|c|}{ Trajectory } & \multicolumn{1}{c|}{ Right } & \multicolumn{1}{c|}{ Left } & \multicolumn{1}{c|}{ Total } \\
\hline TO groove $\longrightarrow$ Trachea posterior half. & $37.5 \%$ & $68.2 \%$ & $52.2 \%$ \\
\hline Trachea posterior half. & $33.3 \%$ & $13.6 \%$ & $23.9 \%$ \\
\hline TO groove $\longrightarrow$ Trachea posterior half $\longrightarrow$ Trachea anterior half & $8.3 \%$ & $4.6 \%$ & $6.5 \%$ \\
\hline TO groove $\longrightarrow$ Thterior half (ITA directed down from above) & $4.2 \%$ & $4.6 \%$ & $8.7 \%$ \\
\hline TO groove $\longrightarrow$ An & $0.0 \%$ & $2.2 \%$ \\
\hline Oesophagus $\longrightarrow$ TO groove & $0.0 \%$ & $4.6 \%$ & $2.2 \%$ \\
\hline Anterior to Trachea & $0.0 \%$ & $4.6 \%$ & $2.2 \%$ \\
\hline Non recurrent & $4.2 \%$ & $0.0 \%$ & $2.2 \%$ \\
\hline
\end{tabular}

Abbreviation used; TO - Tracheo Oesophageal

\section{Discussion}

This analysis illustrates the variability of surgical anatomy of RLN. None of the patients showed clinical features of RLN damage during the post operative period. The surgical method we adopted allowed us to identify RLN in all patients while preserving the nerve functions postoperatively. Careful dissection was found to be superior to palpation method where there is higher rate of nerve injury (1).

The relationship of the RLN and inferior thyroid artery has shown a regional variation. A Chinese study showed that $80 \%$ of right and $91.5 \%$ of left RLNs to travel posterior to the inferior thyroid artery (2). A Brazilian study observed that in most instances RLN to travel through the branches of inferior thyroid artery (3). Furthermore, absent inferior thyroid artery was detected in $4 \%$ instances.

In most studies the left RLN was found posterior to the inferior thyroid artery compared to right RLN $(2,4,5)$. In our analysis the RLN was posterior to the inferior thyroid artery in most cases $(80 \%$ in left and $50 \%$ in right). The right RLN, however, showed a more variable position. 
Regarding the relationship of the nerve to the ligament of Berry; most of the studies concluded that the nerve is found within 3-4mm of the ligament (1). Our study was comparable with this finding having $54 \%$ of RLNs in contact with the ligament and $37 \%$ traveling in between the ligament and the TO groove. We found that $3(7 \%)$ RLNs were traveling through the ligament.

The trajectory of the RLN was highly variable. Even though it is described under 8 categories sub types do exist (table). The RLN was more constantly found in the TO groove on left side (77\%) at the level of the inferior thyroid artery. The right RLN showed a more variable position with $63 \%$ lying in the TO groove at the inferior thyroid artery level.

\section{Conclusion}

Careful dissection and exact identification of the RLN during thyroidectomy reduces the risk of nerve damage. Exploration of the RLN first around the inferior thyroid artery and in the case of failure around the ligament of Berry is acceptable. Knowledge about the variable relationship between RLN, inferior thyroid artery and ligament of Berry helps identification of RLN during thyroidectomy. The trajectory of the nerve from the inferior thyroid artery level to the level of ligament of Berry is highly variable. Presence of the right non recurrent laryngeal nerve should be expected.

\section{References}

1. Altorjay A, Tihanyi Z, Luka F, Juhász A, Bencsik Z, Rüll M, Kecskés G, Paál B. Place and value of the recurrent laryngeal nerve (RLN) palpatory method in preventing RLN palsy during thyroid surgery. Head Neck 2009; 31(4): 538-47.

2. Uen YH et al. Surgical anatomy of the recurrent laryngeal nerves and its clinical applications in Chinese adults. Surgery Today 2005; 36(4): 312-315.

3. Bernardo Almeida Campos, Paulo Roberto Ferreira Henriques. Revista do Hospital das Clínicas 2000; 55(6): 195-200.

4. Kaibogaku Zasshi. Relationship between the recurrent laryngeal nerve and the inferior thyroid artery in Japanese. Surgery1988; 104(6): 977-984.

5. Sultana S.Z. et al. Morphological study of recurrent laryngeal nerve in relation to thyroid gland. Mymensingh MedJ2006; 15(2): 192-6. 